Thomas Hylland Eriksen. Steps to an ecology of transnational sports. Global Networks 2007, vol 7(2), pp 154-165. ISSN 1470-2266.

The definitive version of this article is available at http://www.interscience.wiley.com/ http://dx.doi.org/10.1111/j.1471-0374.2007.00162.x

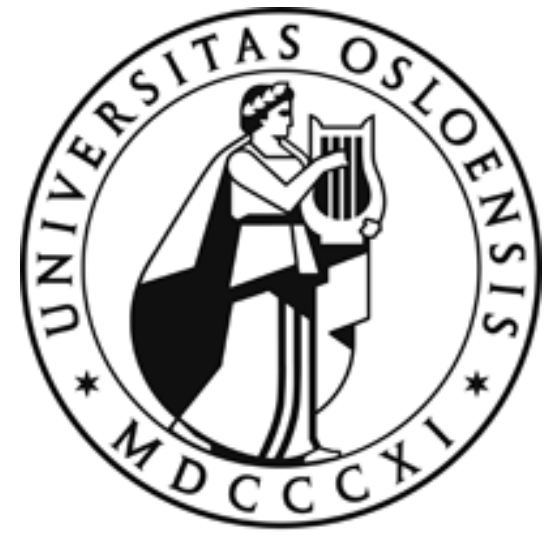




\section{Steps to an ecology of transnational sports}

THOMAS HYLLAND ERIKSEN

\section{Why do some phenomena spread while others do not?}

Descriptions of global networks and transnational flows tend to account for themselves by discussing a number of necessary conditions for them to come about, such as the deregulation of capitalism, the development of instantaneous communication technologies and modernization processes that, at least to some extent, standardize consumer preferences. Yet necessary conditions are never the same as sufficient conditions, and I have often wondered why some phenomena travel whereas others do not. Sometimes, the explanation is straightforward - Coca-Cola has a larger marketing budget and more local agents than Irn-Bru; Chinese-made plastic toys are cheaper than Japanese-made plastic toys, and so forth - but such explanations do not always work. Why Microsoft has developed a near-monopoly in the office software market is mysterious, given that competition continued until as late as the 1980s, and nothing about Microsoft's products appeared to be superior to anyone else's. On the other hand, as the evolutionary biologist Stephen Jay Gould (1989) has shown in his detailed analysis of the mass extinctions of the Burgess Shale, evolution involves chance and necessity, and circumstances, which may be dubbed bad timing and bad luck, and may render sophisticated and initially well-adapted species extinct. 'The fittest', which by definition survives under selective pressure, may be the beneficiary of climatic change rather than inherently superior genes. Some 150,000 years ago, humans were in fact so rare that they would easily have made it onto the endangered species list of today (Grinde 2002: 73). Many species survive through occupying marginal niches in ecosystems dominated by stronger species, others by adapting to deserts.

By analogy, when concepts, ideas, activities and commodities spread across the world, they follow courses caused by complex systems of communication, competition and interaction, and by definition, the 'fittest' survive. However, survival need not entail global domination and the annihilation of the competition, but could also refer to the long-term appropriation of a delineated, secure niche.

The channels enabling commodities and concepts to travel are well known from the literature of globalization (for example, Held et al. 1999; Scholte 2005), but if we want to understand why some do and others do not, specific explanations are necessary, similar to the way we understand the long-term appearance and disappearance of natural species. As noted above, fortuitous coincidences may account for the sudden proliferation or extinction of particular species in nature; the same can be the case with cultural phenomena. Malcolm Gladwell's thought-provoking book about 'tipping-points' (Gladwell 2000) shows how extraordinary individuals with personal charisma and large networks may, more or less on their own, set snowballs rolling, tipping the scales in favour of one particular product or idea, be it Hush Puppies shoes or swing jazz. Given the right circumstances, that is. Sometimes, it appears that a product or idea spreads largely by virtue of its intrinsic qualities, such as a bank offering (and actually paying out) a considerable reward for a modest investment. If the entrance ticket is too high, only a small audience is prepared to pay it, and therefore Madonna is better known than Boulez, although both have been globally disseminated into very different niches. (Ants are more common than elephants, Boulez fans will be quick to point out, but they have shorter life spans.)

As a writer producing much of my work in a small language (Norwegian), I have a special personal interest in trying to discover the ecology of popularity and translations in the book world. What is it about Dan Brown's novels that makes them so attractive to so many people, who are otherwise very different? The short answer is that The Da Vinci code at a certain time reached a tipping point in its sales, following 
which it became a bestseller everywhere because it had been established as a bestseller in a particular location first, where it appeared at the right time when the appropriate niche was vacant. Why is Jostein Gaarder the only contemporary Norwegian author with a large global readership? Reviewers at home do not regard his books as major achievements; when a jury made a list of the 25 best Norwegian novels of the last 25 years in summer 2006, none of his books were included. Nevertheless, the Norwegian novelists who are routinely described as Nobel Prize material by the domestic press are hardly translated and rarely read outside Scandinavia. Leaving substance and detail aside, it should be clear that the quality of a book, or a record, is not a main criterion for its global dissemination or lack thereof. Nor is there an inverse relationship between quality and dissemination; any idea to the effect that consumers follow the path of least resistance is insufficient, since there exist many easily digestible cultural products that never take off.

Some phenomena are big at home and unknown abroad; some are deeply globalized yet unknown among the masses; and others become well known, popular and familiar worldwide. There is scarcely a general, satisfactory answer to why this is the case, but a few possible factors can be mentioned provisionally: globally popular phenomena (i) require little culturally specific knowledge - they have a short learning curve; (ii) have an emotional, sensory or intellectual appeal which transcends local concerns; and (iii) are effectively marketed transnationally. In other words, low common denominators, a cheap entrance ticket and immediate gratification are factors facilitating global dissemination. The hamburger, the rock song and the thriller, as generic forms, are examples of cultural products that satisfy these requirements.

\section{Sport and natural selection}

Let us now turn to sport. There exists an extraordinary number of sports in the world, many of them transnational in the sense that world championships are organized regularly, they have an international governing body and national associations in all six continents. At the same time, what is interesting on the basis of the above discussion is their differences in terms of attention from the media, spectator interest, economic turnover and number of active participants, as well as their transnational distribution. Some sports have large numbers of participants worldwide but few spectators or media coverage; with other sports, it may be the other way around. Some sports are huge, in terms of both popular interest and participation, in limited parts of the world, and virtually non-existent elsewhere. The media in most countries tend to concentrate intensively on a few sports such as tennis, certain track \& field disciplines and, of course, football, with a sprinkling of golf, swimming, ice hockey and other sports. The dominance of football in many parts of the world has led to the relative marginalization of other sports, just as the brown rat has almost entirely displaced the black rat in most of Europe and North America. In the majority of countries in Europe, Latin America and Africa, football dominates the newspapers' sports pages, sport on television and adolescents' sport activity, clearly to the detriment of other, often traditional sports with less transnational appeal, glamour and economic might. The qualities of football, or its 'magic', have been explored by many excellent writers inside and outside of academia (Archetti 1999; Armstrong and Giulianotti 1997; Foer 2006; Giulianotti 1999; Kuper 1994); nevertheless, the attention of audiences tends to be a zero-sum game, and when the floodlights illuminate the football field, everything else is left in the dark. Football is not the only culprit in the presently skewed ecology of sports, but it has a privileged position in large parts of the contemporary world. The starting point for my exploration of a few non-globalized or recently marginalized sports, is that the kind of competition they face from the more spectacular sports can be likened to a natural selection process, and the question is how and to what extent these sports 
manage to survive in an era where transnational fame can easily come to overshadow local recognition.

\section{Unevenly spread sports}

There is a deep irony, often commented upon, in the fact that the United States, often seen as the main source of global culture, despised by middle classes everywhere else, is almost an island unto itself when it comes to team sports. The largest spectator sports in the USA are baseball, American football, basketball and ice hockey, and none of them can be considered truly global in their reach. Ice hockey is confined to cold countries, and basketball is an unimportant sport in most countries (with Lithuania and Croatia as interesting exceptions in Europe). Baseball and American football, although played in some countries outside the USA, are considered 'American' in the rest of the world. European football (soccer) is popular among adolescents and women in the USA, but it has to date not succeeded commercially. Indeed, successful American soccer players look to Europe for career opportunities. There is a parochialism to the world of sport in the USA which goes against the conventional wisdom about American cultural imperialism (cf. Marling 2006 for other examples). One partial explanation for the non-spread of typical American sports could be that the niches they might have filled had already been taken by other sports at the outset of 'the American century'. Cricket in Britain and the British Empire, for example, goes far back in history, and would not be ousted by baseball. Cricket is, incidentally, itself an interesting case of an unevenly spread sport. Apart from a few newcomers such as the Netherlands, cricket is seriously played only in the New Commonwealth countries, and all ten test-playing nations have a British imperial history. Its popularity in the Indian subcontinent matches the enthusiasm for football seen in Latin America. Just as football seems to be played wherever there are a few square metres with no traffic in a Brazilian city, cricket is played by children on village dirt roads and in the back-alleys of Indian cities. For subcontinental diasporic groups as far from the source as in Scandinavia, the weekly cricket matches give them a rare opportunity for a noncontroversial recreational activity that simultaneously strengthens their cultural (and male) identity (Walle 2005).

On a trip to India in 1992, I had left Norway with an awareness of the mediaproduced impression that the Winter Olympics in Albertville were a global sport event. Arriving in Bombay, I immediately discovered that a parallel event of much greater global import was taking place simultaneously, namely the cricket World Cup. These two domains - the world of winter sport and the world of cricket - were both presented as global and were almost entirely oblivious of each other.

Such unevenly spread transnational sports as cricket and winter sports (including bandy, biathlon, Nordic combined etc.) create conditions for a selective cultural geography in the countries involved. West Indians, living in cricket-obsessed countries, are acutely aware of the geographical location of New Zealand and Zimbabwe, but are likely to have vaguer notions of where Mali and Belarus are. Norwegians know a thing or two about Slovenes (home to some of the world's best ski jumpers) but may have less to say about Slovaks. Finns have vivid notions about Canadians (because of ice hockey and bandy), but generally have far less clear ideas about New Zealanders. Baseball, curiously, could have given Cubans and Americans a non-conflictual field of interaction and a pretext for deepening mutual knowledge, had it not been for the American embargo. The transnational networks developed selectively through sports, thus, create structures of relevance that can be exploited for other purposes. In spite of the incessant media talk about not mixing sports and politics, they are far from being independent entities. As an Iranian colleague comments (Alghasi 2006), 
before the 2006 football World Cup, television channels worldwide produced brief presentations of the participating countries. As he points out, the short documentary from Mexico on Norwegian state television depicted happy people in colourful costumes waving Mexican flags and cheering on their national team. The documentary from Iran, however, focused largely on the earthquake-ravaged city of Bam. There were no smiles or flags there, and nobody who talked about football. In other words, the pre-World Cup introductions of the countries taking part were far from innocent. All sports presuppose a great deal of tacit, or recipe, knowledge among their supporters. The lyrical ambiguity in the title of C. L. R. James's classic book on cricket and colonialism, Beyond a boundary (James 1963), was lost on almost anyone outside the New Commonwealth. Outside North America, Babe Ruth is either unknown or recognized as some obscure American athlete, and many foreign readers of Stephen Jay Gould's essays in natural history understand everything he says except when he begins to develop parallels between evolution and baseball.

\section{Small fish in big ponds}

With football, many boundaries dissolve, and its increasingly transnational character makes the relationship to territory and identity a complex one. Before the 2006 World Cup, I discovered that my son (who was then nine) disapproved of the Swedish striker Zlatan Ibrahimovic. I wondered if he had already developed a scepticism towards Swedish athletes (the friendly rivalry between Sweden and Norway in sport goes back a hundred years), whether the reason might be Zlatan's controversial personality or heaven forbid - that it had anything to do with Mr Ibrahimovic's Yugoslav origins. Eventually, it turned out that the problem was that Zlatan played for Juventus, a team my son disliked. As a faithful Gunners supporter, he rooted for France in the World Cup, since Arsenal's star player Thierry Henry had a pivotal place in the French squad. The intensely transnational character of contemporary football, through widespread knowledge about the great leagues of England, Germany, France, Spain and Italy, makes it difficult to continue being a large fish in a small pond. Teams are now compared transnationally, the transfer market is emphatically international (increasingly so after the famous Bosman case in 1996, which loosened the restrictions on foreign players in European teams), and on most elite teams, there are few players with local origins (but see McGovern 2002 for a modification of this view). The Antwerp team Beveren indeed reached the Belgian cup finals in 2004 with a team consisting largely of players from the Ivory Coast. There are about two English players on Arsenal's 2006/2007 first team (in 1990, there was one non-English player), and the French national team that won the 1998 World Cup was famously led by Zinedine Zidane, a player of Algerian origin. The entire team was dominated by players with non-French origins, and was accordingly denounced by the nationalist leader Jean-Marie Le Pen as 'artificial'. During the 2006 World Cup, Le Pen repeated this view by suggesting that 'maybe the coach exaggerated the proportion of players of color and should have been a bit more careful' (Zirin and Cox 2006). Apart from the fact that Le Pen refuses to learn about French demography, this shows that fish about to outgrow the local pond are sought out by the owners of bigger ponds, and thus racial purity becomes an ecological impossibility in football at the highest level. In the icy waters along the northern coast of Norway, a fertile ground for all kinds of marine life, the smallish local crabs are currently facing stiff competition for food and space from invading Russian giant crabs. The very same process is taking place in football too; the giant crabs of Juventus and Real Madrid are conquering the hearts of small-country football supporters through television, transfers and travel. The small endemic crabs have to devise a survival strategy.

Being a star footballer in a small national league means, to players and spectators 
alike, that one didn't succeed in securing a contract with a team of real importance one has by definition remained in the margins of the ecosystem. Our local club, FC Lyn Oslo, depends on Icelanders, Swedes and Nigerians for its (modest) successes. Its sports director frankly admitted that when they brought 17-year old Nigerian talents into the club, they saw it as an investment, hoping that when the players matured, they could be sold with a nice profit to a team in England or Italy. In fact, in 2006, FC Lyn made a profit of about $£ 4$ million (a substantial sum for a Norwegian club) when they sold the young Nigerian John Obi Mikel to Chelsea (following an unpleasant legal wrangle involving two agents and Manchester United). In this kind of world, there is little security and stability for anyone. As Bill Buford comments in his book on football hooliganism, Among the thugs (Buford 1992), a Man U supporter who had tattooed Bryan Robson's name on his forehead had performed a very daring stunt indeed, because who knew if Robson wouldn't be sold to another club next season? As the system boundaries expand, the former centre is suddenly relegated to a central location in a minor subsystem. Local clubs have traditionally functioned as farmer teams for national elite clubs like FC Lyn, feeding them with talent and reaping modest profits from the transfers; but the latter now increasingly see themselves as farmer teams for transnationally respected clubs. The Omani national goalkeeper Ali al-Habsi seems to be better off, economically and in terms of prestige, as Bolton's second goalkeeper than he was when, during his years in FC Lyn, he was the best goalkeeper in the Norwegian league. When transfer windows close, local managers express disappointment rather than pleasure if they have been unable to sell some of their most gifted players.

The growth of transnational media (such as Eurosport and Sky Sport) has increased the familiarity of football supporters with players in other countries, and the annual European tournaments make direct comparisons between teams easy. Another important factor is, of course, the differences in economic power between clubs in Europe: most have to settle for the second best when the market is transnational and no primordial club loyalties are expected of players.

Using the analogy from ecological and evolutionary thinking, we may now begin to consider the alternatives, not for the smaller football clubs, but for the other team sports living increasingly in the shadow of football.

\section{Big fish in small ponds}

Hunters and gatherers surrounded by agriculturalists who slowly move closer, eventually colonizing and domesticating their traditional hunting grounds, have traditionally been forced to withdraw to ever more barren and marginal territory. Some, however, become assimilated into the farming community. Others devise new ways of surviving. In the world of sport, football and a few other sports are the invaders; football is like the English language or franchised shops, creating a global conversation at the expense of removing diversity. In most of the world today, even children have an acute awareness of where the fame and money is. The scramble for Europe now under way in Africa consists in no small part in attempts by young boys to be discovered by a football scout (Bale 2004). In European societies, people involved in other sports often complain about the disproportionate attention given to football in the media and as a result, by sponsors.

What would be an ecologically sound and sensible reaction to this kind of predicament? Competing in the same field as the dominant ones (with broken English, or with inadequate ploughing tools)? Surprisingly many do, notwithstanding the clear hierarchy between national football cultures. Some withdraw to their shrunken territory, while others posit an alternative sport culture based on values other than global fame and money. 
Being a locally valued footballer does have its benefits. The star players in the Norwegian league make the headlines domestically just as often as their British or Spanish counterparts do - just as locally valued authors are solemnly and respectfully interviewed by all the domestic media, their books are praised and awarded prizes. The fact that these media are perused by a fraction as many readers as the large European media, or that the prizes are relatively valueless outside the country, does not necessarily detract from the thrill of being a big fish in, admittedly, a small pond. Some footballers, as well as writers, try their hand at international career-building, and a few succeed reasonably well. The vast majority are nonetheless condemned to remain at home, reaping the not negligible benefits of being world-famous in Norway. Footballers can keep up appearances with a decent showing in domestic matches, unlike tennis players, whose global ranking is everything. Yet, as I have argued, being a big fish in a small pond is increasingly difficult, as that pond is no longer an entity unto itself.

\section{On marginal land}

Some sports which were popular and prestigious a few decades ago have dwindled dramatically. In the 1970 s, Scandinavian newspapers still regularly covered the national and international championships in orienteering. This sport evolved out of the boy scout movement, and consists of tracing a route and finding posts in a varied, usually forested area, with the help of a map and a compass. Not exactly a spectator sport, orienteering nevertheless had its stars 30 or 40 years ago, whose names and faces would be recognized in the post office. Today, the national and international championships are still organized, and more than 30 countries have national orienteering federations, but one would be hard pressed to find a trace of glamour there. While researching this essay, I came across the names of the leading orienteerers, both male and female, of our day - I had heard of none of them before, not even the Scandinavians. However, orienteering was never huge in any way. With speed skating, the decline has been more dramatic in northern Europe. For 80 years - the first eight decades of the twentieth century - speed skating was an undisputed national sport in Norway and the Netherlands. Swedes, Finns, Russians, Germans and others also competed in a serious way, and their domestic media duly covered the international championships, but it was only in the Netherlands and Norway that the sport had a popularity comparable to that of football. The peculiar links between countries with similar sporting affinities mentioned earlier, flourished in the world of speed skating, and Dutch and Norwegian skaters often learned each others' languages, sometimes even marrying into the other country.

Demanding patience and concentration from the spectators, a classic skating championship would take a weekend. Beginning on Saturday morning with the $500 \mathrm{~m}$ sprint followed by the $5000 \mathrm{~m}$ distance in the afternoon, skaters raced in pairs drawn according to a ranking system based on their recent performances. The points at the end of the first day (where 500 metre seconds and 5000 metre seconds were weighted so that one $500 \mathrm{~m}$ second equalled ten $5000 \mathrm{~m}$ seconds) decided who would qualify for the final 10,000 metre, that is the 16 best after the first day.

Sunday began with the intermediate $1500 \mathrm{~m}$ distance, followed by the marathon 10,000 metres - 25 laps on the 400 metre track (skating arenas were often used for track \& field in summer). The 10,000 metre race was an endurance test both for skaters and onlookers. Each pair took a quarter of an hour, and frequently, an ice preparation machine had to be run over the rink to even out the surface. In Norway (unlike the Netherlands, with its milder winters and more artificially frozen rinks), competitions invariably took place outdoors. Many of us were frozen to the bone by the time of the finishing ceremony. 
In the 1960s and 1970s, on the weekends of a big competition, the Friday newspapers printed forms where audiences, most of them watching television or listening to the radio, could fill in the lap times, finish times, and calculate their own, 'unofficial' points. Everyone seemed to follow ice skating in those days. Even today, many Norwegians remember, or remember having been told about, the Swedish janitor who decided to prepare the ice during the World Championship in 1963, just before the Norwegian favourite, Knut Johannessen ('Kuppern') ran the decisive 10,000 metres. As a result of this decision, many Norwegians have continued to believe to this day, that the Swede Jonny Nilsson won the championship. Some 30 years on, the television channels broadcast only edited or partial versions of the big championships, which have been forced out of their once comfortable niche. The national championship is hardly covered by the press at all. For a while in the 1980s, it was difficult even to find a shop in Oslo that stocked speed skates. As Norwegians began to win medals and championships again in the 1990s, public interest grew slightly, but the sport as such, a symbol of Norwegian winter sport along with cross-country skiing since independence (1905), has now become a quaint and old-fashioned activity in the eyes of many Norwegians.

There have been attempts to revive speed skating by making it more viewerfriendly. Suggestions have been made to remove the 10,000 metre distance and to replace it with 3000 metres. Championships in single distances are now arranged, as it is believed that the attention spans of spectators have become shorter. Short track skating (much faster, more explosive and more television-friendly than the elegant long-track version) has been introduced with some success in Canada and East Asia. In spite of these attempts, there can be no doubt: like orienteering, speed skating is past its days of glory. Both sports are slower than their competitors and difficult to adapt to the viewing rhythms encouraged by multi-channel television. Among the winter sports, alpine skiing and spectator-friendly novelties such as freestyle skiing have grown much faster than anything else over the last 20 years, finding ecological niches where the older, slower sports had to give in. In order to follow a skating championship with any level of enthusiasm, one has to sit through it from beginning to end, since there are so many figures and possibilities to keep track of. Notwithstanding the climatic difficulties, speed skating has too much complexity - the cultural entrance ticket is too expensive, and it lacks the television-friendly explosiveness of the competition - to retain its position in the new media situation. Speed skating is probably to a great extent a victim of postmodern television, not of football. It has been forced onto the barren wastelands and is, today, unable even to produce a medium-size fish in its shrunken pond.

\section{Defending viable niches}

Several team sports involve a grassy field, two goals and a leather ball. Rugby, American football and soccer are the most familiar ones to most of us. However, Australian rules football is hugely popular in Australia (and nowhere else). Originally developed for cricketers to keep in shape during the winter months, in the same way as bandy in the Nordic country was often, in the day of amateurs, played by men who were footballers in summer, the game resembles both rugby and football (soccer) but has its own circuits of competition, prestige and money.

The two national sports in Ireland deserve special attention here. My own interest in the non-globalized sports began on a trip to Ireland when I discovered, glancing through the Irish newspapers, that Gaelic football and hurling were given wider coverage than soccer. This is in spite of the fact that the Irish are no less connected to the world of global communication than anyone else in Western Europe, and have a decent national football team for a country with less than four million inhabitants. 
The popularity of the entirely, and stubbornly, national sports of hurling and Gaelic football is initially puzzling. Why would a young aspiring athlete choose a sport that does not get him anywhere? It is said that if you are on the team that wins the Irish championship in either sport, you will never have to pay for a pint at your local for the rest of your life. Yet there are no large sums of money involved in these sports, nor is there an international transfer market. It is as though a young shark chose to stick to his diet of shrimp rather than moving up to tuna.

Hurling and Gaelic football are extremely fast, demanding and very physical sports. Gaelic football could be described as an amalgam of rugby and soccer, although the Gaelic Athletic Association (GAA) emphasizes that it predates both these games. Hands are allowed, there is no offside rule, and the goals resemble rugby goals. In hurling, the same field is used as in Gaelic football, but the game uses a smaller ball (called a sliotar) and a stick (the hurley). Both are hugely popular sports in Ireland, in terms of both participation and audiences. The GAA has more than 2,500 clubs in Ireland alone.

How can this be, in a world and, certainly, a continent where minor sports have so often been sidelined by the predatory presence of football? The answer seems to be partly political, partly strategic.

On the website of the GAA (www.gaa.ie), we learn that: 'The Gaelic Athletic Association (GAA) was founded on November 1st 1884, by a group of spirited Irishmen who had the foresight to realise the importance of establishing a national organisation to revive and nurture traditional, indigenous pastimes.' The establishment of the GAA was a nationalist response to British imperialism - Ireland remained a colony until 1922 - and the organization promotes Irishness just as much as sport. The GAA's official guide states, as one of its goals, to 'actively support the Irish language, traditional Irish dancing, music, song, and other aspects of Irish culture'. There are even nationwide competitions in some of these cultural activities. The province of Ulster (Northern Ireland), politically a part of the United Kingdom, participates in both hurling and Gaelic football tournaments, but just as Northern Irish Catholics never (or hardly ever) play soccer at a higher level, Protestants do not participate in the Irish sports. Unlike contemporary soccer clubs, the Gaelic sports recruit players from their home area, although, as the GAA informs, 'in certain cases, e.g. universities, the club will represent an organisation or institution and will draw their players from the members of that organisation' (www.gaa.ie/page/organisation.html).

The political dimension of Gaelic sports explain, at least to some extent, their popularity in the late nineteenth and early twentieth centuries, when Irish nationbuilding had to be anti-British in order to be viable. Since the British had football and rugby, the Irish had to come up with something else. Interestingly, the Argentines followed the exact opposite strategy in the early twentieth century (Archetti 1999). While not a British colony, Argentina was dominated economically by the British at the time, and instead of positing an alternative, they decided to beat the British at their own game (which they succeeded in doing as early as the 1920s). While the Irish behaved like hunter-gatherers who sharpened their spears and improved their bows when the farming peoples drew near, the Argentines were like hunter-gatherers who rapidly took on the new technology and excelled at it.

Gaelic sports have carved out an entirely local niche that has proven to be locally competitive and internationally insulated in an era where everything seems to militate against that which is merely local. In a strategically wise move, the GAA have fixed the tournaments to the period when football is asleep, that is the summer months, reaching a climax in September. This sounds like good ecological thinking, good Darwinian sense. The motivations of the players who choose a career in Gaelic sports rather than in transnational sports are bound to be complex; partly cultural nationalism, 
partly big-fish-in-small-pond.

Why has speed skating not succeeded in the same way? For one thing, it was never monopolized by a single nation and could not easily be used in nation-building.

For another, it lacks the visceral qualities, the speed and the violent imagery, of the Gaelic sports, which they in turn share with football. In spite of their emphatically local character, Gaelic sports have retained the magic of football. The latter has become a symbol of a smaller world; the former are used to instil emotions in a selfconscious small nation on the margins of Europe.

\section{Conclusions}

The sociologist George Ritzer (2004), in his original and entertaining book The globalization of nothing, contrasts 'the grobalization of nothing' with 'the glocalization of something', which he sees as the two main faces of globalization. In many ways, contemporary football fits his description of 'grobalization of nothing', the neologism grobalization being a fusion of growth and globalization. National distinctiveness in football has been reduced because of shared, similar aims - to win international tournaments - and the rationality of industrialism has entered the field (see Dobson and Goddard 2001 on the economics of contemporary football). In the last World Cup, the most entertaining teams were, in the opinion of many, some of the African ones, who were unceremoniously defeated, apparently because of the poor organization of their defence. Commentators around the world complained that the tournament was generally boring, that the best teams were better defenders than attackers, and that the most boring team of all ended up winning.

Such subjective comments are always debatable; the point is that this was a widespread sentiment. With Gaelic football and hurling, the situation is very different, but this does not mean that necessarily they conform to Ritzer's notion of 'the glocalization of something', by which he means a product, a service, a place or a person with substantial local content, but which is entwined in global networks. In fact, these sports represent something that cannot, and will not, be globalized because they symbolize a cultural identity that is by default associated with a particular place. Unlike folkloric cultural products elsewhere, including several regionally based sports, Gaelic sports are not marketed overseas (but are played in Irish diasporas). While foreign visitors to matches are welcomed, they are not numerous, and the games are not aggressively marketed as tourist attractions. They are there for internal use. Ritzer's sociology of globalization needs a third term to grasp this kind of phenomenon, which is exclusively local.

In the context of the Darwinian selection and ecological niche-thinking used above to make sense of the uneven globalization of sports, Ritzer's approach, along with other theories of globalization, is limited because it rules out the possibility of anything being merely local. Although the world of transnational flows in sport is arguably less spatially bounded than most of the world's ecosystems, the selfcontained, local system continues to exist, by carving out a niche where there is sufficient nourishment and no external competition. In football, however, such niches have become difficult to defend due to the intensification of transnational flows and 'the spectre of comparisons' (Anderson 1998).

\section{References}

Alghasi, S. (2006) Personal communication.

Anderson, B. (1998) The spectre of comparisons: politics, culture and the nation, London: Verso.

Archetti, E. (1999) Masculinities: football, polo and the tango in Argentina, Oxford: Berg. Armstrong, G. and R. Giulianotti (eds) (1997) Entering the field: new perspectives on world football, Oxford: Berg. 
Bale, J. (2004) 'Three geographies of African football migration', in G. Armstrong and R. Giulianotti (eds) Football in Africa: conflict, conciliation and community, London: Palgrave Macmillan, 229-46.

Buford, B. (1992) Among the thugs, New York: W.W. Norton.

Dobson, S. and J. Goddard (2001) The economics of football, Cambridge: Cambridge

University Press.

Foer, F. (2006) How football explains the world, London: Arrow.

Giulianotti, R. (1999) Football: a sociology of the global game, Cambridge: Polity.

Giulianotti, R. and R. Robertson (2004) 'The globalization of football: a study in the

glocalization of the "serious life", The British Journal of Sociology, 55, 545-68.

Gladwell, M. (2000) The tipping point: how little things can make a big difference, London:

Abacus.

Gould, S. J. (1989) Wonderful life: the Burgess Shale and the nature of history, New York:

W.W. Norton.

Grinde, B. (2002) Darwinian happiness: evolution as a guide for living and understanding

human behaviour, Princeton: Darwin Press.

Held, D., A. McGrew, D. Goldbaltt and J. Perraton (1999) Global transformations, Cambridge:

Polity.

James, C. L. R. (1963) Beyond a boundary, London: Yellow Jersey Press.

Kuper, S. (1994) Football against the enemy, London: Orion.

McGovern, P. (2002) 'Globalization or internationalization? Foreign footballers in the English league, 1946-95', Sociology, 36, 23-42.

Marling, W. H. (2006) How 'American' is globalization?, Baltimore: Johns Hopkins University Press.

Ritzer, G. (2004) The globalization of nothing, London: Sage.

Scholte, J. A. (2005) Globalization: a critical introduction, 2nd edition, London: Palgrave.

Walle, T. M. (2005) “"Cricket is my passion!" The non-recognition of masculine space in the days of the "Muslim Monster", Paper presented at CASCA conference, Translocality: discussing culture and change in the 21st century, Mérida, 3-8 May.

Zirin, D. and J. Cox (2006) 'French soccer and the future of Europe', www.edgeofsports.com, 6 July. 